\title{
Caracterização de Óleos Alimentares pelo Perfil de Trigliceridos
}

\author{
HIGUINALDO J. CHAVES DAS NEVES*
}

Embora as técnicas e normas de controlo de qualidade em alimentos preveja métodos de controlo e avaliação para os óleos alimentares, casos há em que estas se revelam insuficientes para a determinação de origem e detecção de alterações, ou adulterações, de modo inequivoco. Se os óleos são fundamentalmente constituidos por trigliceridos é legítimo pensar que o seu conjunto em cada óleo corresponderá a um perfil típico. 0 estudo dos perfis cromatográficos para os trigliceridos de óleos de soja, girassol, milho, graínha de uva, azeite e bagaço de azeitona, obtidos por cromatografia gás-líquido de alta resolução a temperatura elevada (HT-HRGC) mostra-se adequado à caracterização e identificação expedita de óleos alimentares. A aplicação de métodos gráficos de representação directa de perfis globais, assim como 0 tratamento dos dados cromatográficos por métodos computorizados de análise de perfil envolvendo agrupamento hierárquico ou análise de componente principal, permitem um reconhecimento visual imediato dos perfis característicos para cada óleo, identificação qualitativa de desconhecidos e reconhecimento de adulterações.

\section{INTRODUÇÃ̃O}

0 controlo de qualidade de óleos alimentares baseado na determinação dos ácidos gordos é frequentemente prejudicado pelo facto de que os valores obtidos podem encontrar-se dentro dos intervalos quantitativos aceites, apesar de adulteração. Alguns óleos apresentam composições semelhantes em ácidos gordos e mesmo do insaponificável e não podem ser facilmente diferenciados. Tal diferenciação exige análises comparativas sistemáticas de esteróis, tocoferóis e alguns trigliceridos [1]. A introdução de fases líquidas com grupos $\mathrm{OH}$ terminais [2] e 0 desenvolvimento de tecnologia de fabrico de colunas capilares capazes de suportar temperaturas até $400^{\circ} \mathrm{C}$ torna possivel a análise de trigliceridos por cromatografia gás-líquido de alta resolução, em que os trigliceridos de idêntico número de carbono (separação CN) podem ser separados de acordo com o número de ligações duplas (separação NUFA). A instabilidade dos trigliceridos a temperaturas elevadas prejudica tradicionalmente a sua análise cromatográfica por técnicas de injector quente. Esta dificuldade pode ser hoje circulada pela aplicação de técnicas de introdução de amostra que evitam o choque térmico, nomeadamente pelo uso do vaporizador de temperatura programada.

Alguns óleos não são fáceis de diferenciar apenas na base do perfil de trigliceridos tal como determinado pela análise cromatográfica. 0 aforismo "um desenho vale mais do que mil palavras" apresenta-se como uma realidade contundente nestes casos em que um elevado número de dados numéricos é obtido. As diferenças e semelhanças subtis perdem-se no amálgamado das tabelas numéricas. Uma das mais despercebidas, mas mais eficientes capacidades do cérebro humano, é o reconhecimento de perfis. 0 objecto observado é decomposto nas suas caracteristicas e apenas as essenciais à construção de um modelo são retidas. No conjunto, nada é mais diferente do que um S. Bernardo e um Chihuahua. No entanto, ambos são de imediato reconhecidos como cães. Esta

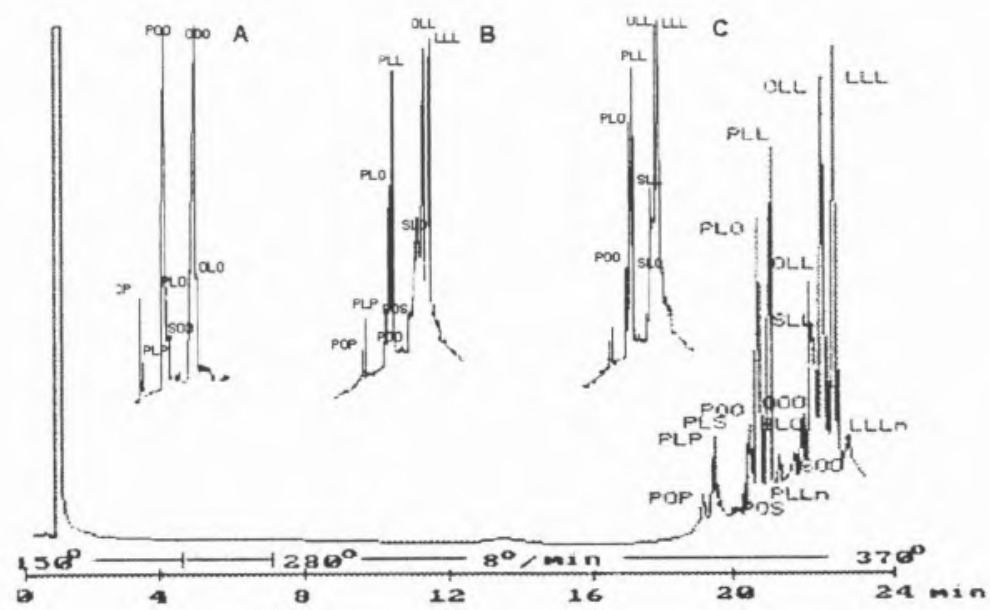

espantosa capacidade do cérebro humano para o reconhecimento de perfis pode ser utilizada com enormes vantajens no tratamento de dados analíticos para a caracterização de produtos complexos (objectos) e visualização de semelhanças e diferenças entre os elementos de um conjunto. Tal pode ser conseguido meramente pela apresentação dos dados de forma gráfica ilustrativa de apreensão imediata ou recorrendo a métodos matemáticos mais complexos como são os métodos multivarietais. Em ambos os casos, e com niveis de informação diferentes é possivel obter informação rápida sobre a natureza de um óleo e possíveis adulterações, apenas com base na análise dos perfis de trigliceridos.

\section{OS PERFIS CROMATOGRÁFICOS}

A Figura 1 mostra os perfis cromatográficos dos trigliceridos dos óleos de soja, de oliva, de girassol e de grainha de uva. Se bem que a inspecção dos croma-

Figura 1 - Perfil cromatográfico de trigliceridos de azeite (A), óleo de girassol (B), óleo de graínha de uva (C) e óleo de soja. Injector: vaporizador de temperatura programada. Coluna: capilar de vidro, $10 \mathrm{~m} \times 0,25 \mathrm{~mm}$ d.i. revestido com OV-17-OH, $d_{1}=0,25 \mu \mathrm{m}$. Detector DIC Os trigliceridos são assinalados por uma notação baseada nas iniciais dos ácidos gordos constituintes: $P$-palmítico, S-esterárico, 0-oleico, L-linoleico. 


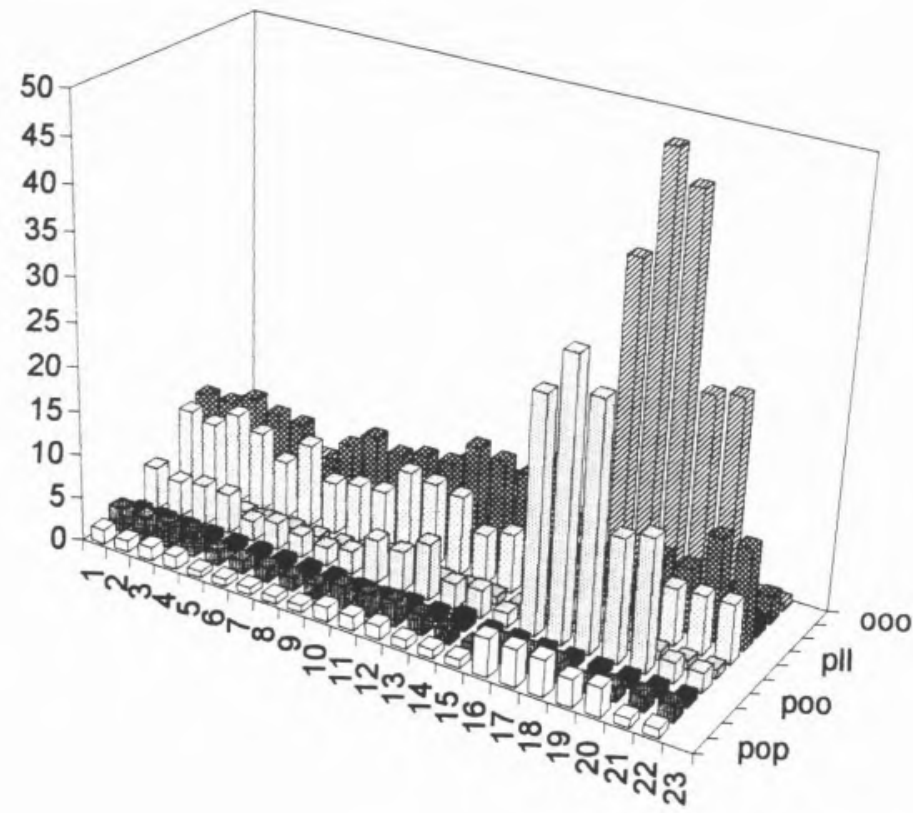

Figura 2 - Concentrações relativas (\%) de trigliceridos em óleos alimentares. 1-4- óleos de soja; 5-9-6́leos de girassol; 10-12-óleos de milho; 13-15-óleos de grainha de uva; 16-18-Azeites; 19-20- óleos de bagaço de azeitona; 21-22- óleos inespecificos ("óleo vegetal").

togramas permita distinguir claramente entre 0 óleo de oliva (azeite) e os restantes, já as diferenças entre os óleos de grainha de uva e de girassol são pouco claras. A comparação dos valores numéricos correspondentes às concentrações relativas dos diferentes trigliceridos em cada óleo é ainda mais equivoca dada a semelhança de valores, por um lado e a elevada quantidade de números numa tabela em que os óleos são descritos pelos valores conjuntos de 15 trigliceridos. Com esta quantidade de dados torna-se difícil, senão impossivel, extrair informação útil. Uma alternativa será a representação gráfica dos resultados. Experimentemos então, um clássico gráfico de barras tal como exemplifica a Figura 2. 0 único padrão verdadeiramente reconhecivel é 0 que respeita às elevadas concentrações de P00 e 000 nos óleos de oliva (16 a 21). No entanto, a quantidade de informação que se pode obter a partir dos mesmos dados aumenta significativamente se for adoptado um modo de representação que tire partido da nossa capacidade de reconhecer padrões globais. Existe um número elevado de representações gráficas computorizadas em que os objectos descritos por um conjunto de variáveis (os segundo as "caras de Chernoff".
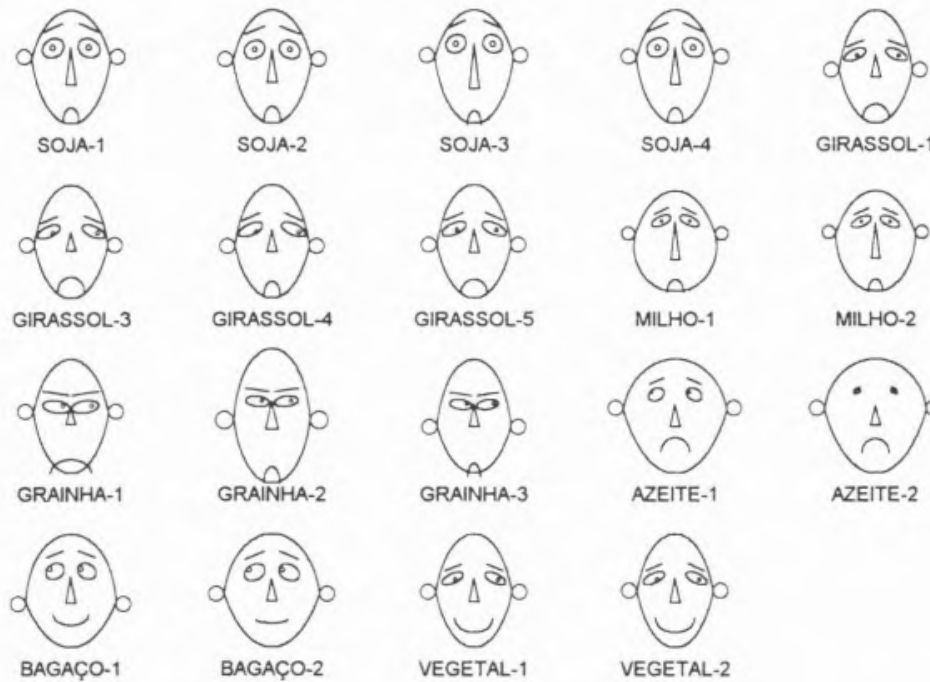

GIRASSOL-1
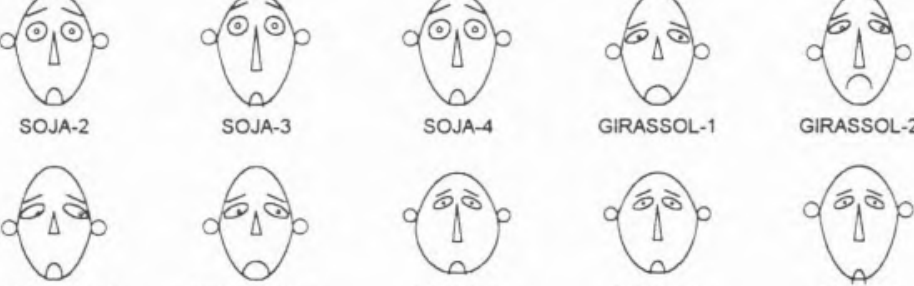

GIRASSOL-4

GIRASSOL-5
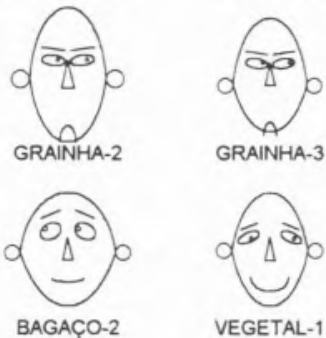

VEGETAL-
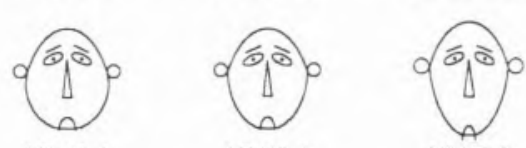

MILHO-1

MILHO-2

MILHO-3
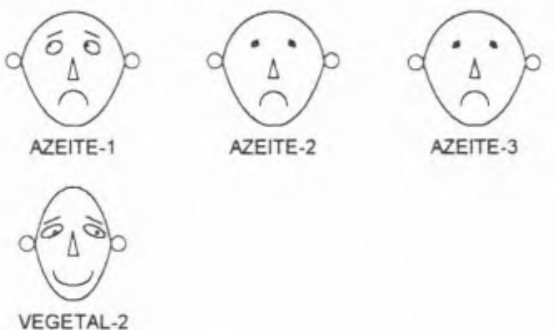

VEGETAL-2

Figura 3 - Representação de óleos alimentares pela projeç̧ão das concentrações relativas (\%) de trigliceridos

óleos descritos pelos seus trigliceridos) podem ser perfigurados sob formas geométricas reconheciveis em que cada elemento representa a dimensão de uma variável. Na Figura 3 os óleos alimentares analisados em função dos trigliceridos são representados pelas populares "caras de Chernoff". O significado de cada elemento facial consta da legenda. As semelhanças e diferenças entre cada um dos óleos representados é, agora, mais evidente. óleos de idêntica origem facilmente apreensivel. A utilidade deste sistema para a identificação dos óleos é evidente. Se um óleo desconhecido pertence a uma das classes referenciadas, a sua identificação pelo perfil de trigliceridos assim representado é imediata. Tal é exemplificado com os óleos designados por vegetal-1 e vegetal- 2 .

\section{MÉTODOS NUMÉRICOS- ANÁLISE MULTIVARIETAL}

Até aqui, aplicaram-se técnicas subjectivas para 0 reconhecimento de perfis capazes de reconhecer semelhanças e diferenças entre objectos similares. 


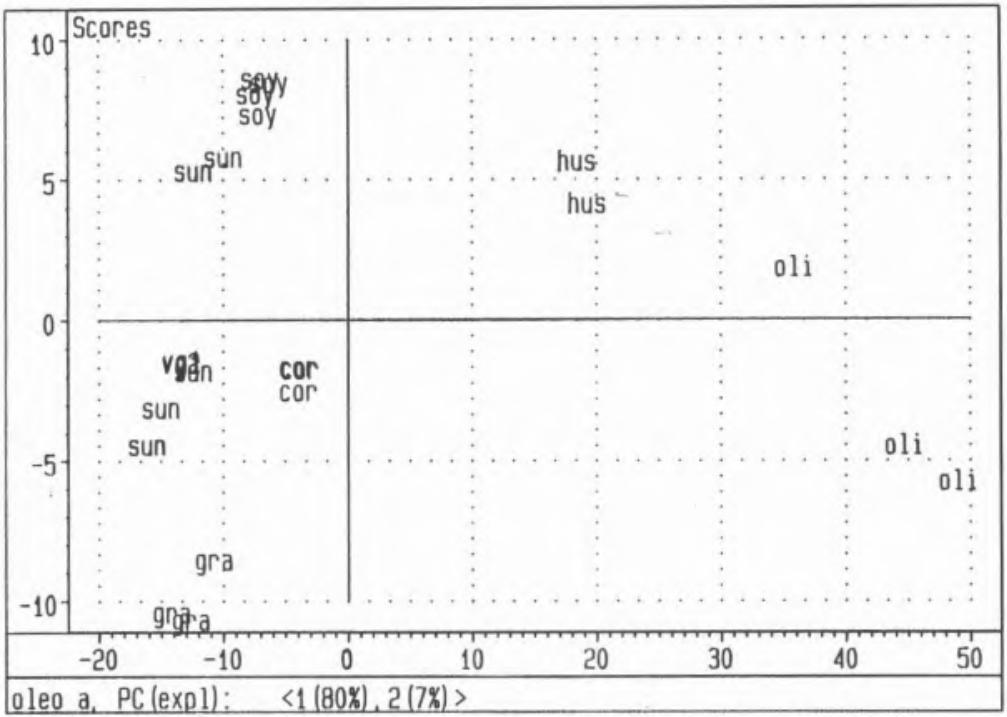

Figura 4 - Dendograma de agrupamento hierárquico pelas distâncias euclidianas de óleos alimentares segundo a composição relativa (\%) em trigliceridos.

Um objecto é diferenciado de outro por um conjunto de propriedades que 0 tornam particular. Quando o mesmo conjunto de propriedades (perfil) é qualitativamente comum a um conjunto de objectos similares, define-se uma familia de objectos que podem tender a formar sub-grupos de acordo com o peso relativo de cada uma das propriedades descritivas. Pode-se, deste modo, determinar valores para cada uma das propriedades características do conjunto e aplicar uma técnica matemática para obter uma classificação objectiva, naquilo a que se chama taxonomia numérica. 0 objectivo é o de organizar dados observados em estruturas com significado informativo quanto à sua natureza e relações entre os objectos. Quando os dados contêm uma estrutura clara em termos de agrupamento de objectos, tal é reflectido na ramificação de uma árvore hierarquica, frequentemente chamada dendograma. 0 dendograma representa as dissemelhanças entre os objectos quando agrupados. Para a construção do dendograma representado na Figura 4, cada óleo é considerado como um objecto descrito por um conjunto de variáveis (os valores de concentração relativa dos trigliceridos). 0 cálculo de agrupamento hierárquico (distancias euclidianas) revela a formação de agrupamentos principais, cada um contendo ainda subgrupos que, em última análise, caracterizam cada um dos tipos de óleo tratados (oliva, grainha de uva, girassol, milho e soja). A grande semelhança entre os óleos de graínha de uva e giras- num espaço $n$-dimensional podem se conseguidos através da análise de com- sol é patente. Os óleos de origem indedos com ("vegetal") aparecem agrur tipo de óleos, de acordo com a sua orição seja mais difusa. Por outro lado, das trar que apenas algumas variz classificativo, o tempo e o trabalho gastos na análise limitar-se-á apenas ao necessário para a determinação daquelas. Deste modo, redução a n variáveis e observação mais eficiente dos objectos ponente principal (PCA). Nesta técnica cada objecto passa a ser descrito por um único valor (primeira $\mathrm{PC}$ ) em lugar de variáveis $\mathrm{x}_{1}, \mathrm{x}_{2}, \ldots \mathrm{x}_{\mathrm{n}}$

$$
\mathrm{PC}=a \cdot x_{1}+b \cdot x_{2}+\ldots c \cdot x_{\mathrm{n}}
$$

Este valor é calculado de modo a reter a máxima variância. Uma segunda $\mathrm{PC}$, se necessário, deverá ser calculado ortogonalmente ao primeiro e explicar tanto quanto possivel a variância residual não explicada pelo primeiro e assim sucessivamente. Torna-se, deste modo, possivel uma representação bi ou tridimensional dos dados de modo a que as relações entre os objectos seja observável ao olho humano e, por outro lado, a grandeza e sinal dos coeficientes $\boldsymbol{a}, \boldsymbol{b}$...c (loadings) fornece uma indicação àcerca do significado das variáveis na formação da estrutura.

A Figura 5 mostra as relações entre os óleos num plano de projecção definido por duas componentes principais que, no seu conjunto, explicam $87 \%$ da variabilidade total. A primeira PC (absissas) distingue claramente os óleos de oliva. A segunda PC (ordenadas) é responsável pela diferenciação dos restantes entre si. Todos os óleos formam agrupamentos bem localizados em áreas do espaço bidimensional. Mais uma vez, as semelhanças entre os óleos "vegetal"

Figura 5 - Classificação de óleos alimentares pelo perfil de trigliceridos (15 variáveis) por análise de componente principal. Soy- Soja; Sun- Girassol; Cor-Milho; GraGrainha de uva; Hus- Bagaço de azeitona; Oli-Azeite. Primeira PC (absissas) versus segunda PC (ordenadas)

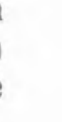




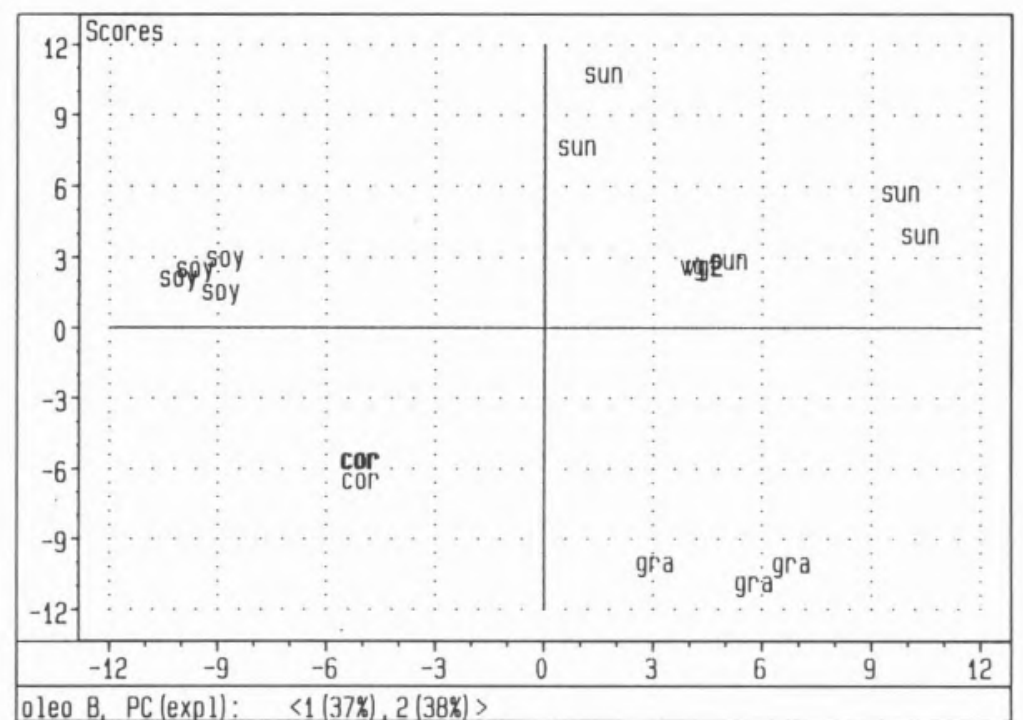

Figura 6 - Classificaçāo de óleos alimentares pelo pertil de trigliceridos (15 variáveis) por análise de componente principal. Soy-Soja: Sun- Girassol; Cor-Milho; GraGraínha de uva. Primeira PC (absissas) versus segunda $\mathrm{PC}$ (ordenadas).

com o óleo de girassol são patentes. A separação entre os azeites e os óleos de bagaço de azeitona é suficiente para poder ser útil na detecção de suspeitas de adulteração daqueles por estes, mas a sensibilidade do método não foi ainda determinada.

Figura 7 - Classificação de óleos alimentares pelo perfil de trigliceridos ( 5 variáveis: 0OL, OLL, LLL, PLL e SLL) por análise de componente principal. Soy- Soja; SunGirassol; Cor-Milho; Gra- Grainha de uva;. Primeira PC (absissas) versus segunda PC (ordenadas)
É claro que a diferenciação entre óleos de oliva e os restantes, não necessita de processos complicados. Eles são bem diferenciáveis pelas suas características sensoriais. A capacidade classificativa do modelo parece ser melhorada quando os óleos de oliva não são considerados (Figura 6). Neste caso, cada uma das duas componentes principais tem uma contribuição igualmente efectiva na classificação dos objectos embora, no seu conjunto, apenas $75 \%$ da variabilidade total seja explicada. A separação entre cada uma das categorias é mais ampla. A classificação dos óleos desconhecidos (vegetal) como sendo óleos de girassol é confirmada. A maior dispersão espacial dos óleos de girassol não é surpreendente e denuncia de modo claro a observação empirica.

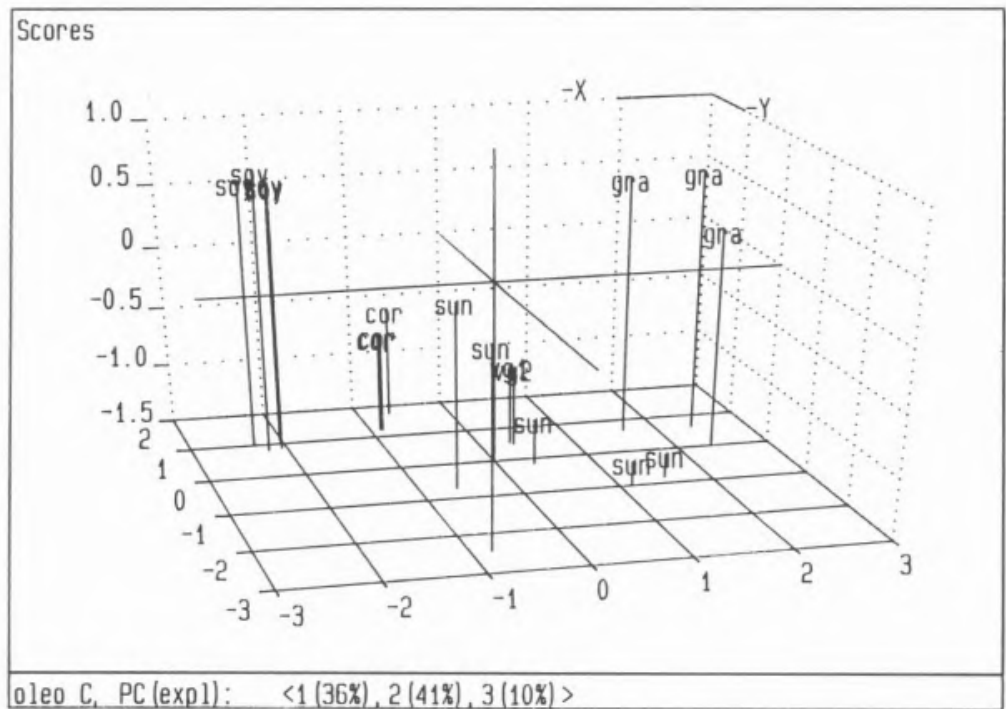

•Departamento de Química, Faculdade de Ciências e Tecnologia, Universidade Nova de Lisboa, 2825 Monte da Caparica

\section{REFERENNCIAS}

1. P.Y. Vigneron, M. Audegond, P. Delvoye, M. Levacq, A. Monseigny, B. Stoclin, Rev. Fr. Corps Gras. 33 (1986) 359.

2. E. Geeraert, P. Sandra, HRC \& CC 8 (1985) 415 .

3. H.J. Chaves das Neves, A.M.P. Vasconcelos, HRC \&CC 12 (1989) 226 